\title{
Thermal infrared pictures and the mapping of microclimate
}

\author{
W. J. Derksen \\ Laboratory of Physics and Meteorology, Agricultural University, Wageningen, \\ the Netherlands
}

Accepted: 10 April 1974

\begin{abstract}
Summary
Airborne infrared line scanning (IRLS) provides us with pictures from which conclusions about earth surface temperatures may be drawn. This paper discusses the interference of micrometeorological parameters with the interpretation of these pictures as well as the possibility of some relevant characteristics of microclimate to be estimated from these pictures.
\end{abstract}

\section{Introduction}

Research in micrometeorology has nearly always been based on measurements of profiles above a limited number of points in the field. The matter of how representative these measurements are for larger areas (advection, oasis effects) has most often been evaded by speaking about large homogeneous areas. At best this problem has been tackled by discussing change of profiles of wind, water vapour and temperature after the air passes a discontinuity between two large homogeneous areas. Theory for these cases is complicated enough, and to check theories and models the choice of studying these cases is adequate. Nevertheless the question rises as to what extent real surfaces can in practice be considered as homogeneous.

Also there are many cases in which mosaics of fields with different characteristics alternate even with small patches of forest and separate trees. In these situations not only several boundary layer separations may exist but also the problem of wake flow comes in. About the latter very little is known in field conditions.

Some impression of the variability of the parameters has been obtained by moving instruments through the field on a motor vehicle which gives a number of data lines over the area. Generally for a quick survey roads have to be used which have their own influence on microclimate. Passing traffic may also give a disturbance by mixing the air layers. Recently the method of infrared line scanning has become available to produce a picture in outgoing radiation from the earth's surface in the wavelength range 8-12 $\mu \mathrm{m}$, which, accepting some reasonable assumptions about emission coefficients, may be interpreted as a picture of differences in surface temperature. Though in most micrometeorological work surface temperature has not been measured because of experimental difficulty it takes in fact a central place in energy balance considerations.

In the following the possibility of characterizing microclimates with the help of infrared line scanning (IRLS) pictures will be discussed, together with the importance 
of meteorological parameters as disturbing factors in the interpretation of the pictures for other objectives.

\section{Characterizing microcimate by surface temperature}

Most often the characteristic temperature chosen in describing microclimate is air temperature because this is unambiguous and is most easily measured. In some cases the importance of the temperature of a freely radiating surface is felt: grass minimum thermometers. Indeed surface temperatures more closely reflect the condition a living object is exposed to than does mere air temperature. Surface temperature includes the effects of radiative exchange with the surroundings as well as sensible and latent heat transfer from the surface. If the surface belongs to a body with large heat capacity there is the further complication of exchange of heat between the surface and the interior (e.g. bare soil). The heat content of the body, available for this purpose, depends on the storing history. No conclusions are possible without some knowledge of 'past weather'. We suggest to collect this knowledge, by exposing a standard body (or two) and thus limit the amount of weather observations necessary in the period preceding the flight.

With objects of small heat capacity (vegetation) the surface temperature closely reflects the short-time micrometeorological changes of the moment. If the object can freely evaporate water its temperature also includes humidity conditions, otherwise only radiation and sensible heat transport. Microclimate is characterized by extremes and amplitudes rather than by averages of the parameters. Therefore measurements at moments when these extremes occur are most appropriate to characterize microclimate.

This problem will be discussed in more detail in the section 'Timing of flights'. In the following section first general problems in interpretation of IRLS pictures will be discussed, especially the influence of the atmosphere and of the emission coefficient of the surface. Next the cases of bare soil and vegetation cover will be treated separately.

Some remarks about timing of flights, use and limitations of mathematical models precede a discussion of some pictures as an example of this kind of application. IRLS pictures are obtained by registration (in its simplest form photographically) of the output of a sensor revolving around an axis in the flight direction of the aeroplane. The sensor registers radiation within a small solid angle (some mrad) and a limited wavelength range, for which an atmospheric 'window' is chosen, e.g. 8-12 $\mu \mathrm{m}$. In this window atmospheric absorption and emission is small and may be corrected for to obtain radiation emitted and reflected by the surface of the earth. With sufficient knowledge about emission coefficient and incident radiation on the surface its temperature may be inferred.

Geometric distortions of the image may be corrected for in the process of data handling. This is mainly important in the case of large water surfaces or very monotonous land surfaces like some deserts. In most applications the simple direct photographic registration (sensor-steered synchronously rotating crater lamp blackening film) gives an image on which specific objects can easily be located by visual comparison with a detailed map. In these pictures the scale across the flight direction changes with distance from the vertical projection of the aeroplane and differs from the scale in the flight direction. 
Though generally the scanner position is stabilized separate from the plane there remain some small corrections due to roll, pitch and yaw of the aeroplane. If the position of the aeroplane is carefully registrated during the flight these corrections can also be applied automatically in the data processing stage. Atmospheric absorbtion and emission in the 'window' will lead to a positive or negative correction depending on the temperature profile of the air. The correction that may amount to several degrees centigrade is important when the absolute value of the surface temperature is wanted, for instance in evaporation calculations. It will not be very different for different earth surfaces and may often be neglected in the interpretation of IRLS pictures where temperature differences are shown (Lorentz, 1968).

After correction for atmospheric absorbtion and emission the output of the sensor 1s a known function of

$$
\mathrm{W}={ }^{\prime \prime}{ }_{\lambda_{1}}^{\lambda_{2}} p_{\lambda} \varepsilon_{\lambda} \mathrm{E}_{\lambda}(\mathrm{T}) \mathrm{d} \lambda+\omega{ }_{\lambda_{1}}^{\lambda_{2}} \varphi_{\lambda}\left(1-\varepsilon_{\lambda}\right) \mathrm{B}_{\lambda} / \pi \mathrm{d} \lambda
$$

in which $\omega$ is the opening angle of the sensor, $\varphi_{\lambda}$ the spectral sensitivity of the sensor $\left(\varphi_{\lambda}=0\right.$ for $\lambda<\lambda_{1}$ and $\left.\lambda>\lambda_{2}\right), \varepsilon_{\lambda}$ the spectral emission coefficient of the object, $\mathrm{E}_{\lambda}(\mathrm{T})$ the spectral emissivity of a blackbody, given by Planck's law, $\mathrm{B}_{\lambda}$ the inciding radiation from the surroundings and sky.

Differences of emissivity $\varepsilon$ in the relevant window are important as soon as surfaces other than vegetation are observed and the temperature of the surroundings differs appreciably from that of the surface (e.g. with clear sky). Values of $\varepsilon$ range from 0.97 for vegetation to about 0.90 for dry sand and granite leading to corrections of several ${ }^{\circ} \mathrm{C}$ in the case of dry sand and clear sky (Buetner \& Kern, 1965).

\section{Bare soil}

Regarding soil microclimate farmers sometimes speak about 'warm' and 'cold' soils. The difference is important but should be specified more clearly in a physical way before we can try to detect it in the field with remote sensing methods.

A clear distinction should be made between these ideas of warm and cold soils and temperature criteria used in soil taxonomy ( $7^{\text {th }}$ approximation). These temperature criteria relate to yearly average soil temperature at $50 \mathrm{~cm}$ depth. This parameter is nearly the same for different soils in one climatic region, except for differences due to slope and aspect. It is determined by macroclimate and has a relation to average yearly air temperature.

The temperature of a soil is a result of the energy balance at its surface together with its thermal properties. There will in general be a temperature gradient in the soil; so we will have to specify which depth we are interested in. For root growth a certain ciepth depending on growing stage may be chosen. For night-frost risk the surface temperature decides. Energy exchange processes at the surface and resulting temperatures are cyclic with many cycles (daily, yearly and weather-type cycles) superimposed. In the vague idea of warm and cold soils 'warm' seems to be associated with 'early', 'cold' with 'late', both referring to the spring season (yearly cycle). In this time of seed germination and early growth the layers near to the surface are most important. Surface temperature may be a good characteristic. As regards the yearly 
cycle soils that warm up speedily in spring are those with a small value of the contact coefficient $\lambda \mathrm{C}$. To demonstrate this we give the relation between heat flux density into the soil $G$ and surface temperature $T_{0}$, for two cases that may be used as approximations to actually occurring situations: a sinusoidal variation and a sudden stepwise increase of heat flux density.

With sinusoidal variation $\hat{\mathrm{G}}_{0}, \sin \omega \mathrm{t}$ of the heat flux density into the soil at the surface we find

$$
\mathbf{T}_{\mathrm{o}}=\frac{\hat{\mathrm{G}}_{\mathrm{o}}}{\sqrt{ }(\lambda \mathrm{C}) \sqrt{\omega}} \sin (\omega \mathrm{t}-\pi / 4)\left(\operatorname{van} \mathrm{Wijk}_{\mathrm{i}}, 1963\right) .
$$

With a stepfunction in which the heat flux density suddenly changes from 0 to $G_{0, c}$ at time $\mathrm{t}=0$ and initially homogeneous temperature in the soil we get for the change $\mathrm{T}_{\mathrm{o}}$ in surface temperature:

$$
\mathrm{T}_{\mathrm{o}}=\frac{2 \mathrm{G}_{\mathrm{o}, \mathrm{c}}}{V^{\prime \pi} V(\hat{\lambda} \mathrm{C})} \sqrt{\mathrm{t}} \text { (Carslaw \& Jaeger, 1950). }
$$

In both cases the rate of temperature rise is inversely proportional to the square root of the contact coefficient $\lambda . \mathrm{C}$, in which $\lambda$ is thermal conductivity and $\mathrm{C}=$ p.c. heat capacity per unit volume, $(\mathrm{p}=$ density, $\mathrm{c}=$ specific heat $)$. Table 1 gives values of $1 / V(\lambda \mathrm{C})$ for three soil types and different water contents.

The rate of temperature rise of different soils is further dependent on $\mathrm{G}_{o}$, the heat flux density available for transport into the soil. Though incoming short-wave radiation $R_{s}$ may be supposed to be equal for different soils (except for differences in slope and aspect, to be treated separately), the fraction $\mathrm{G}_{0}$ is dependent on reflection factor $\alpha$ and heat used for evaporation E. Both $\alpha$ and $\mathrm{E}$ are also dependent on moisture content of the soil.

Table 1 also contains some representative values of $(1-\omega)$ and the product $(1-\alpha) / V(\lambda C)$ which determines approximately the rate of temperature rise in a day-time situation without evaporation. It is clear that moisture content of the superficial soil layers is, even without evaporation, the most important factor in determining soil surface tem-

\begin{tabular}{|c|c|c|c|c|c|c|}
\hline & $\begin{array}{l}\text { Pore } \\
\text { volume }\end{array}$ & $\begin{array}{l}\text { Water- } \\
\text { filled } \\
\text { pore } \\
\text { volume }\end{array}$ & $\begin{array}{l}\lambda \mathrm{C} \\
\left(10^{-3} \mathrm{call}^{-2} \mathrm{~cm}^{-4} \mathrm{~s}^{-1} \mathrm{~K}^{-2}\right)\end{array}$ & $\begin{array}{l}1 / V(\lambda \mathrm{C}) \\
\left(\mathrm{call}^{-1} \mathrm{~cm}^{2} \mathrm{~s}^{\frac{1}{2}} \mathrm{~K}\right)\end{array}$ & $1-\alpha$ & $\begin{array}{l}(1-\alpha) / V(\lambda \mathrm{C}) \\
\left(\mathrm{cal}^{-1} \mathrm{~cm}^{2} \mathrm{~s}^{\frac{1}{2}} \mathrm{~K}\right)\end{array}$ \\
\hline Sand & $\begin{array}{l}0.4 \\
0.4 \\
0.4\end{array}$ & $\begin{array}{l}0 \\
0.2 \\
0.4\end{array}$ & $\begin{array}{l}0.21 \\
2.1 \\
3.64\end{array}$ & $\begin{array}{l}68.6 \\
21.2 \\
16.4\end{array}$ & $\begin{array}{l}0.82 \\
0.91 \\
0.91\end{array}$ & $\begin{array}{l}56.3 \\
19.3 \\
15.0\end{array}$ \\
\hline Clay & $\begin{array}{l}0.4 \\
0.4 \\
0.4\end{array}$ & $\begin{array}{l}0 \\
0.2 \\
0.4\end{array}$ & $\begin{array}{l}0.18 \\
1.4 \\
2.66\end{array}$ & $\begin{array}{l}75.3 \\
26.9 \\
19.3\end{array}$ & $\begin{array}{l}0.84 \\
0.92 \\
0.98\end{array}$ & $\begin{array}{l}63.2 \\
24.7 \\
18.9\end{array}$ \\
\hline Peat & $\begin{array}{l}0.8 \\
0.8 \\
0.8\end{array}$ & $\begin{array}{l}0 \\
0.4 \\
0.8\end{array}$ & $\begin{array}{l}0.05 \\
0.53 \\
1.4\end{array}$ & $\begin{array}{r}143.9 \\
43.3 \\
26.9\end{array}$ & $\begin{array}{l}0.90 \\
0.95 \\
0.95\end{array}$ & $\begin{array}{r}129.5 \\
41.1 \\
25.5\end{array}$ \\
\hline
\end{tabular}

Table 1. Thermal characteristics of some soils. 
perature. In the following we will see that evaporation works in the same direction and enhances this effect.

\section{Situation in the day-time}

If heat is absorbed at the earth's surface it will be distributed over soil and air, according to the energy balance

$$
\mathbf{R}_{\mathrm{l}}+(1-\alpha) \mathbf{R}_{\mathrm{s}}+\mathbf{G}_{\mathrm{o}}+\mathrm{H}+\mathbf{E}=\mathbf{O} \text {. }
$$

Here $\mathbf{R}_{1}$ means net long-wave radiation, $\mathbf{R}_{s}$ incoming short-wave radiation. The sensible heat flux density to the air, $\mathrm{H}$, in normally negative during the day as are $\mathrm{G}_{\circ}$ and the latent heat flux for evaporation $E$. Fluxes are called positive when directed toward the surface.

$\mathrm{H}$ will be determined by the contact coefficient of the air. This contains the turbulent conductivity which is a function of wind speed and stability. Though this may vary a factor 100 or more during the day it will not be very different at any one moment over two soils to be compared. Slight differences could result from the small difference in surface temperature and from differences of roughness of the surface. This latter point will be treated separately with the phenomenon of wind patterns. Normally $\mathbf{H}$ will not vary very much from one soil type to the other, when moisture available for evaporation is comparable.

To estimate differences in net long-wave radiation $\mathbf{R}_{1}$ we may assume back radiation from the sky to be the same for the different soils. Assuming further the emission coefficients for long-wave radiation to be near unity for the different soils we find the difference in $\mathbf{R}_{1}$ per ${ }^{\circ} \mathrm{C}$ difference in surface temperature between two soils to be about $1 \%$ of incoming solar radiation.

$$
\triangle \mathbf{R}_{1}=\triangle\left(\varepsilon \tau \mathbf{T}^{4}\right) \simeq 4 \tau \mathbf{T}^{3} \triangle \mathbf{T}
$$

with $\mathrm{T} \sim 300 \mathrm{~K}$ this becomes

$$
\triangle \mathbf{R}_{1}=0.003 \triangle \mathrm{T} \text { cal } \mathrm{cm}^{-2} \mathrm{~min}^{-1} \text {. }
$$

In the day-time, when solar radiation is present $\left(0.1\right.$ to $\left.1.0 \mathrm{cal} \mathrm{cm}^{-2} \mathrm{~min}^{-1}\right)$, the effect of change of long-wave radiation on resulting temperature is of second order compared with others.

The last factor influencing $G_{0}$ is the evaporation $E$. We are only sure that it will be zero for dry soil, roads etc. If moisture is available at the surface $\frac{E}{(1-\alpha) \mathbf{R}_{\mathrm{s}}}$ may be anything between zero and 1 or even more (oasis condition in desert, A positive), depending mainly on air humidity and wind speed. The importance of $\mathrm{H}$ and $\mathrm{E}$ in determining surface temperature are also shown empirically by the instantaneous change in surface temperature (several degrees) with wind bursts reaching the surface. (See also discussion of wind patterns.)

Evaporation from bare soil will be influenced appreciably by surface structure, drying of the crust, even locally on plowing ridges, etc.

The conclusion from this discussion is that in most circumstances differences in surface temperature will reflect differences in surface moisture (and structure). Sometimes differences in structure are associated with differences in soil type. Only with the help of much additional ground information conclusions about soil type boundaries may occasionally be drawn.

Information about the microclimate, however, is direct. 
Bare soil at night

Nocturnal cooling can certainly not be described by a simple sinusoidal temperature wave. During the night $\mathbf{R}_{\mathrm{s}}=\mathrm{O}$ and $\mathbf{R}_{1}$ nearly constant, though slightly increasing with decreasing soil surface temperature. The situation may be described roughly with the step formula:

$$
\mathrm{T}_{\mathrm{o}}=\frac{2 \mathrm{G}}{V \pi V(\lambda \mathrm{C})} V^{\mathrm{t}}
$$

in which $G$ is now equal to the nearly constant negative net radiation (with clear sky of the order $0.12-0.18 \mathrm{cal} \mathrm{cm}^{-2} \mathrm{~min}^{-1}$, with clouds much smaller). One might argue that at the moment of sunset a gradient in soil temperature exists. In field experiments we find under normal conditions that two times a day the records of soil temperatures at different heights within the uppermost $10 \mathrm{~cm}$ (which is most important) intersect at about the same time in one point. When this happens, once around sunset and once around sunrise) soil temperature is approximately uniform in the uppermost $10 \mathrm{~cm}$. The energy balance is further simplified because the contact coefficient of air in the generally stable situation of a clear night with low windspeed is very small.

Soon surface temperature will drop below air temperature, gradients of water vapour pressure will for some time be small and may later be directed towards the surface. For the energy balance this means that evaporation will be very small (also due to the small turbulent transport coefficient in stable air). Later condensation (dew-fall) may occur, also at a slow rate compared with the evaporation process in the day-time. Though condensation leads to a nivellation of temperature differences, most heat of condensation being delivered to the coolest spots, we may nevertheless trust that those places that would have been the coolest without condensation are still coolest after dew-fall. Only in oasis situations, e.g. moisture-laden air entering a field or forest from one side, the picture may be misleading. In the day-time with important evaporation the situation is much more difficult for interpretation, because places with high cvaporation, now coolest, might easily be hot spots if no water for evaporation were available.

Therefore drawing conclusions about differences in soil type and structure is easier from the night pictures! The lowest temperature is often reached shortly before sunrise. In nights without dew-fall this is also the moment of greatest contrasts.

At the moment of uniform soil temperatures in the evening we will also find that the surface temperatures of different soils and even vegetation are nearly the same. Only roads (no evaporation and large $\lambda \mathrm{C}$ ) and water surfaces (very large $\lambda \mathrm{C}$ ) have still high temperatures at this time. Differences in surface temperature under these conditions will be largely determined by differences in contact coefficient of the soils.

To identify the 'warm' or 'early' soils the best method seems to be to use the late night picture and look for the cold places in a clear calm night. Only the extremely cold places may have to be identified separately because of nightfrost risk. The afternoon picture (see section on timing of flights) may be used, if available, to determine amplitude and average surface temperature distribution. As the 'warm' soils are gene1ally not wet soils, flying for this purpose should be done after several dry days.

Most relations discussed apply to periodic phenomena, such as series of clear days and nights. However, many other cycles exist, like the yearly cycle or 'cycles' due to past periods of clear or overcast weather, or influx of warm or cold air masses. Though generally overrun by the amplitude of the daily variations on clear days these cycles 
may show up in differences of average temperatures. These will be best detected during periods of overcast weather and reflect properties of the deeper subsoil, as the damping depth of a variation is inversely proportional to the square root of the period.

Interpreting these differences due to 'past weather' asks for some knowledge of this past weather. This knowledge may be obtained by observing the weather parameters, including radiation, during a sufficiently long period (several weeks) before flying. In this case much should be. known about the physical (thermal and hydraulic) characteristics of the soil and complicated, and partly uncertain, theory must be applied (computer modelling involved). The knowledge of the limitations of the effects of the 'past weather' may be obtained easier, and probably better, by having in the field some plots or even containers with well-known thermal and hydraulic properties that serve as integrators of all variable weather conditions influencing heat storage (e.g. one wet and one dry sample of standard soil).

\section{Vegetation-covered soils}

The 'surface temperature' of a vegetation cover as observed with scanning techniques is some average temperature of a surface layer of some depth. The effective depth decreases for increasing zenith view angles. During the day there is also an azimuth effect, a sensor looking with the sun giving higher temperatures than one looking against it (because more sun-lit areas are observed; the difference may be several degrees centigrade). The effects are dependent on geometry of the vegatation cover as well as long-wave radiation and sensible heat transport within the vegetation and amount of evaporation at different levels (physiology of the plant coming in). In the future the importance of these effects may be estimated by computer modelling of some extreme cases.

For the night situation speaking about the vegetation as having a 'surface' is less dangerous. The vegetation cover then behaves as a body with a very small contact coefficient as compared to bare soil. 'Storing history' is less important and the surface will reflect clearly the micrometeorological situation of the moment. It will react nearly instantaneously to changes in meteorological conditions like passing of clouds (immediate increase of temperature is observed) or change of wind speed. These changes are observed when one studies surface temperature with a radiation thermometer and also when one compares IRLS pictures taken of the same area with short time intervals, when the 'wind striae' prove to appear not always at the same places, depending on where 'parcels' of air with different speed (and temperature) reach the surface. Though IRLS only provides information about the 'surface' of a vegetation cover we may expect that with some additional information about geometry of the canopy some conclusions about the climate within the cover should be possible. Here again computer modelling of the transfer processes may deepen our understanding of these relations.

It is not likely that the difference between 'warm' and 'cold' soils can be detected on IRLS pictures when the soils are covered with vegetation. Differences in 'surface' temperature due to height, surface cover and density of vegetation are generally much greater than those between different bare soils.

\section{Wind patterns}

On many IRLS pictures interesting features are to be found which we describe as wind patterns. They consist of groups of more or less parallel boundaries of lighter and 


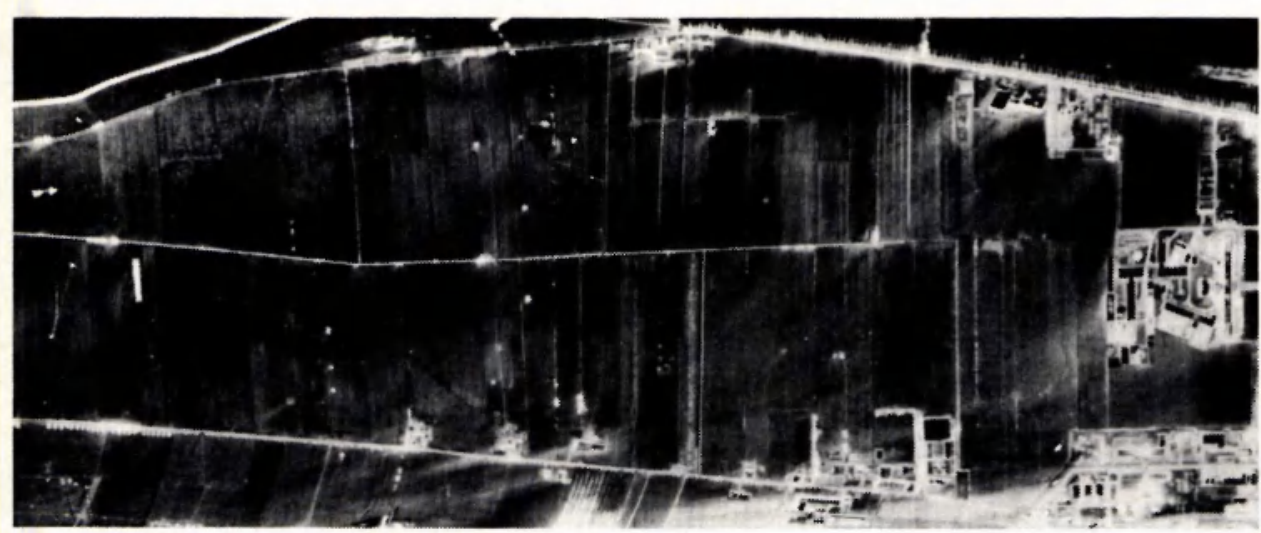

Fig. 1. Part of the 'Binnenveld' near Wageningen, IRLS night picture. Note wind patterns behind obstacles. Grassland. Light tones denote higher temperatures.

darker tones, more or less parallel to the general wind direction. Often they are closely related to objects like trees or houses that mark their upwind end.

The phenomenon may be discussed with Fig. 1 as an example. In this night picture we see the coldest (darkest) spots on grass-covered soils. Bare soil is warmer. Trees (5 to $15 \mathrm{~m}$ high) came out rather warm compared with the cold grass, though they may radiate even more freely than does the grass cover. The explanation is that in a night with low wind speed near the soil and stable conditions sensible heat exchange with the air at the grass level is very low. At the level of the tree crowns the wind speet and sensible heat exchange are such that the tree leaves can be brought near to the higher air temperature at this level.

Now we observe at the lee side of most obstacles like trees and houses two zones of different thermal regime. Near to the obstacle there is a windshade that may be cooler than open exposed surfaces. Further downwind we see how due to wake flow and increased turbulence warmer air from higher levels reaches the surface and heats it. To the sides of the cold wind shade there are also wake-flow effects that show as striae on the surface of the grass.

Wind patterns occur during the night at much lower wind speeds than in the daytıme. Fig. 2 gives an example of wind patterns on a day-time picture. In this case the warm surface is cooled down locally by colder air parcels reaching the surface. The wind speed is higher and though there is the effect of obstacles there are also cases were the relation between the cool patches and obstacles is less clear. In this case the same area was flown again 10 minutes later. Some of the cool patches that were not closely related to obstacles had moved. This probably means that the lower frequencies in the turbulence spectrum give rise to a visible patchy character of surfaces in the temperature image (where cold eddies reach the surface). This is in accordance with spot measurements of surface temperature taken with a 'Heimann' radiation thermometer that show variations of up to $2^{\circ} \mathrm{C}$, cooling being associated with every local rise in wind speed. In fact IRLS pictures taken over a homogeneous terrain can give information on the structure of air movement very near to the surface. In this respect we may think of the 'sheets' postulated by Priestley (1959) or the 'horizontal rolls' 

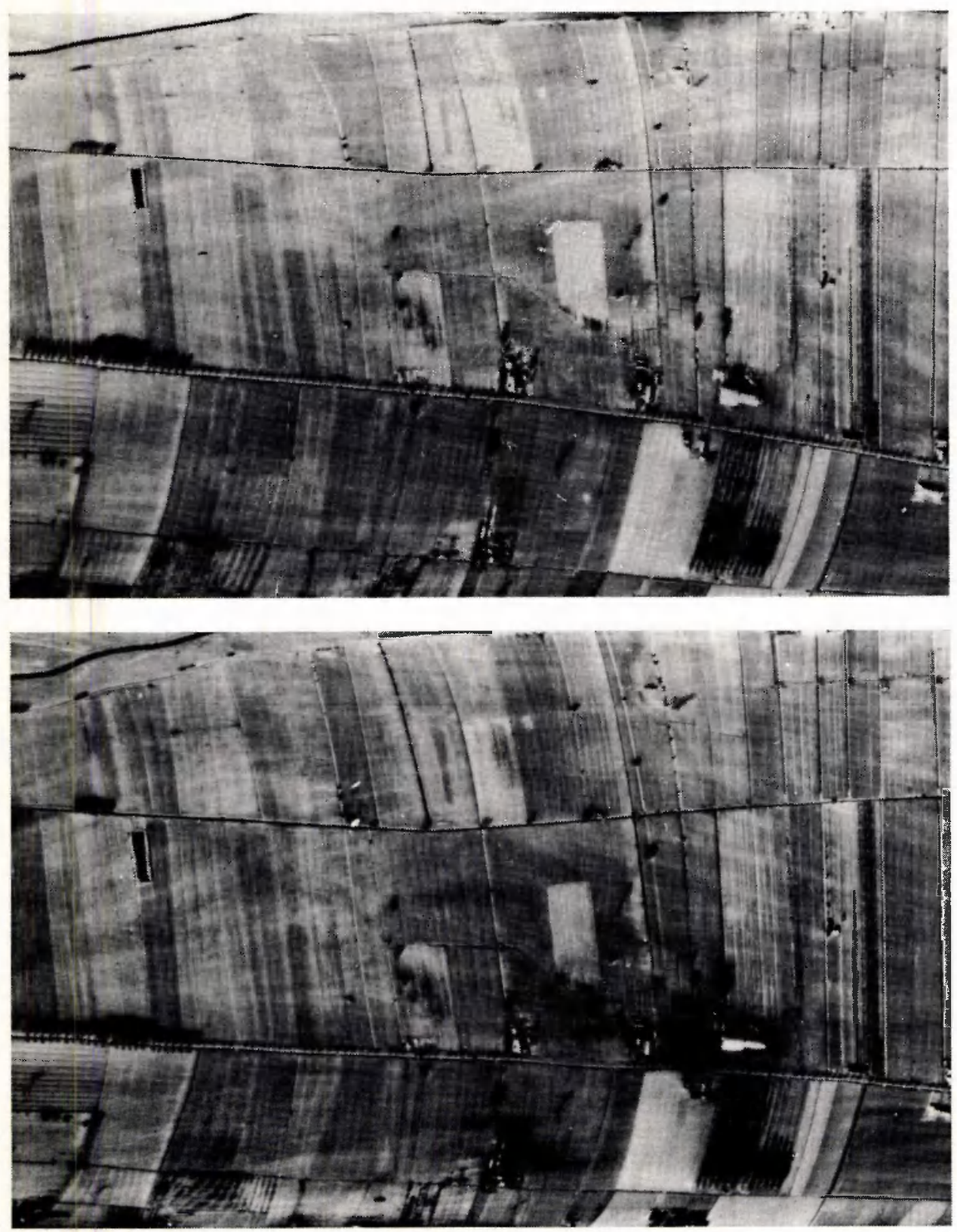

Fig. 2 Two day-time IRLS pictures of a region near Fig. 1; time interval between a and b 10 minutes. In many places the wind patterns have shifted proving that they are rather short-living appearances. In different parts of one picture the striae are not parallel. Grassland. 


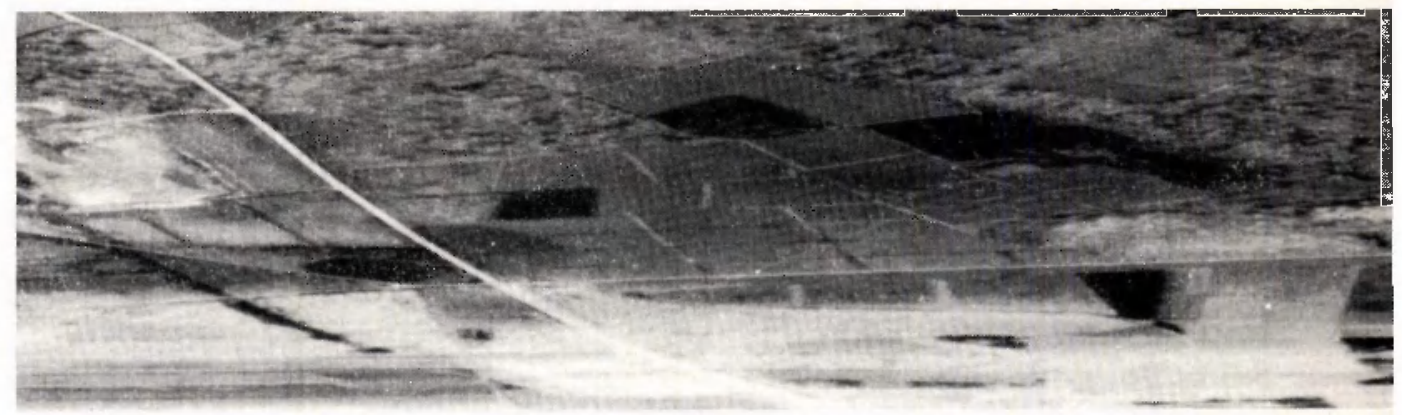

Fig. 3. Pine forests on a slope north of Ede (Vale Ouwe) in light tone (warm) as compared to those at the foot of the hill (upper part of picture). Well-known frost holes can be located on the picture. (Night IRLS picture).

suggested by Businger et al. (1967) when trying to explain peculiarities of point measurements of profiles or fluxes above apparently homogeneous surfaces. The stationary wind shades and wake-flow regions behind hedges, trees, buildings and windscreens give some direct information on the extent of regions of deviating microclimate in these places.

Wind patterns are a complication when pictures are interpreted, for instance for soils reconnaissance. Generally it is possible to identify them by visual inspection and separate them from soil effects. Automatization of this procedure should however be extremely difficult.

\section{Timing of flights}

Microclimate is characterized by its deviations from the average climate of the region, as measured in standard exposition.

There may be a shift in average temperature and a change in amplitude. If we were able to fly at the moments of maximum and minimum temperature we could find both (the average of maximum and minimum is a fair estimate of average temperature). The moment of minimum temperature in the daily cycle is best defined and will not differ much for different soils.

Often the daily cycle of temperature in bare soil (and even in air) on a clear day has been described by assuming sinusoidal variation of the surface temperature. Though some general effects, especially during the day can be described in this way this assumption should certainly not be applied to obtain the moment of minimum surface temperature. This is found experimentally to occur shortly before sunrise, while the minimum incoming radiation flux density is shortly after sunset.

The moment of maximum surface temperature is more difficult to establish and will be different for different soil types and vegetation. This is due to the fact that the distribution of absorbed solar radiation at the surface between $\mathrm{G}, \mathrm{H}$ and $\mathrm{E}$ is dependant on the turbulent exchange coefficient of the air, which may change appreciably during the day. For a vegetation cover the equilibrium between $R_{s}$ and heat loss to the air is most important. In this case the maximum will fall practically at the time of maximum 


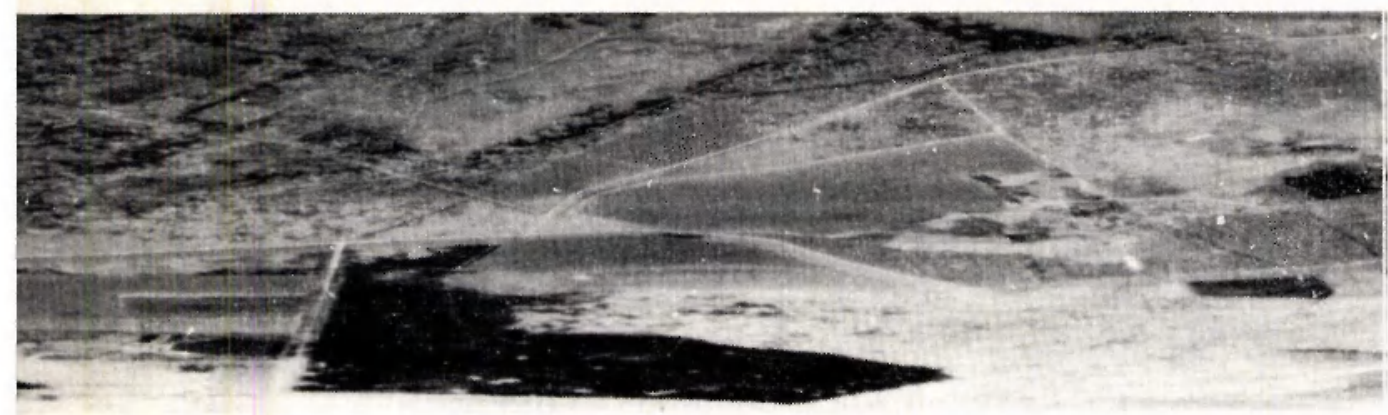

insolation, if other factors, like wind speeds, remain constant. Even though for bare soil the maximum may fall somewhat later it is suggested to fly at this time.

\section{Model studies}

As surface temperature is influenced by so many interdependent parameters one approach to be used in research on the possibility of application of IRLS pictures in discriminating between soils, hydrologic regimes, etc. is to predict surface temperature by computer modelling of the problem, using as much as possible existing knowledge about the transport mechanisms. (For bare soils modelling, sec A. Rozema, Repori NIWARS, in press.)

Through a study of the sensibility of the resulting temperature for variation of separate parameters a certain refinement of several conclusions and suggestions given here may be obtained. There are two limitations to this approach. In the first place the existing knowledge about local surface conditions is limited. Surface temperature is very sensitive to local effects, such as drying of the uppermost surface layer which will nearly stop evaporation. This may occur on one side of ploughing furrows and not on the other; the effect may be different for different orientation of the furrows with respect to the sun. There is also an influence of soil roughness on the wind speed very near the soil. It is very difficult to incorporate these effects in a model since most theories apply to larger homogeneous surfaces.

The second limitation is in the amount of computer time needed. A good period of 'thermal history' has to be simulated for each location. It is clear that such an approach can only be used in a research stage where we try to formulate good rules of thumb for the interpretation of the IRLS pictures for soil science or hydrology. If all these computations, after collection of sufficient field data were to be executed for many locations in the field, the advantage of the remote sensing technique may be lost and it might be faster and cheaper to explore for the features directly in the field.

A different approach from complete modelling is one in which the influence of separate parameters is checked directly either in the field or in a laboratory experiment. Especially for those cases where existing theory and knowledge is lacking this may lead 
to results much faster than does the complete modelling method.

Of course both approaches may complete one another.

For application in microclimatology the use of the IRLS data is much more direct. In any other application one tries to map one of the many parameters that determine microclimatic temperatures. Only in circumstances were one of these parameters overrides the influence of all others conclusions about this parameter may be drawn from the established microclimate. This situation rarely occurs.

\section{Some examples of microclimatic differences shown on IRLS pictures}

On 26 April 1973, 23h00, a flight was made with a Reconofax infrared line scanner over the region from Barneve'd to Schaarsbergen in the Netherlands. On this line many landscapes are crossed: flat country with bare agricultural soil and grassland, bare sand hills, sand hills covered with woods, undulating heather country. The range of surface temperature measured in the field was $5^{\circ} \mathrm{C}$. In this region, heavy night frost is known to occur regularly in a narrow band, a few hundreds of metres wide and many kilometres long (van Goor, pers. commun.). The region is covered to a large extend by pine forest (Pinus silvestris). Frost-sensitive tree species (Douglas fir) are known to have experienced heavy injury in former years. Point measurements in the region showed minimum air temperatures near the vegetation of up to $8^{\circ} \mathrm{C}$ below air temperature in standard exposure during clear calm nights. As this region is situated at the toot of a slope we attribute the phenomenon to flowing of air, cooled by radiation, to the lower parts of the area where cooling then continues.

Fig. 3 shows the region of one of the well-known frost holes as a darker (cooler) area on the picture. Only parts with the same vegetation (pine) should be compared.

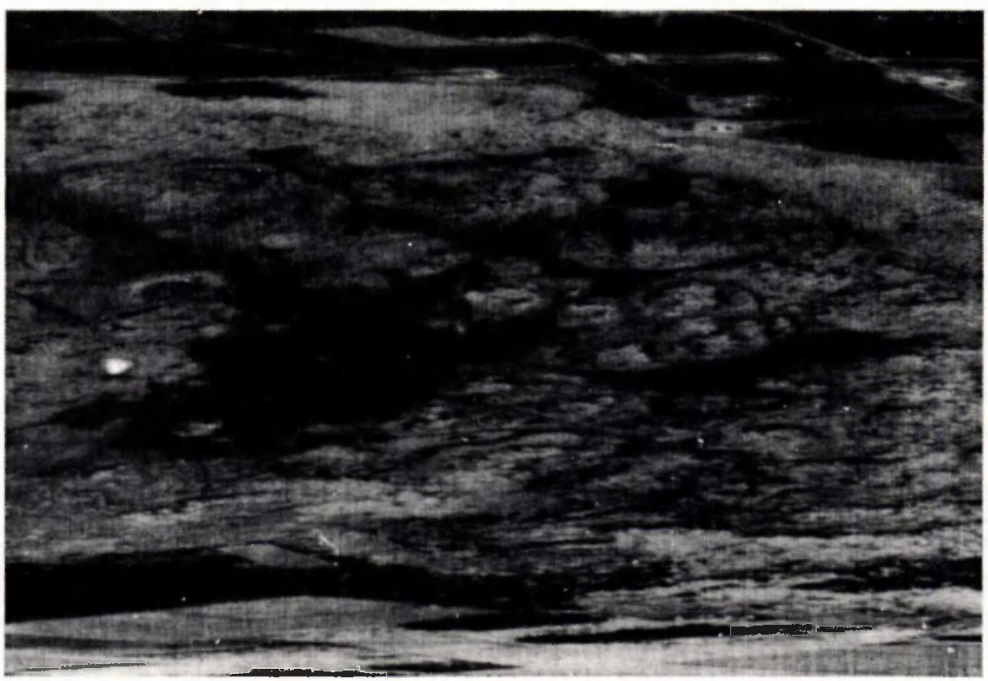

Fig. 4. Bare sand-hill country (Wekeromse zand) during night (IRLS). Lower parts show as darker (colder) areas. 


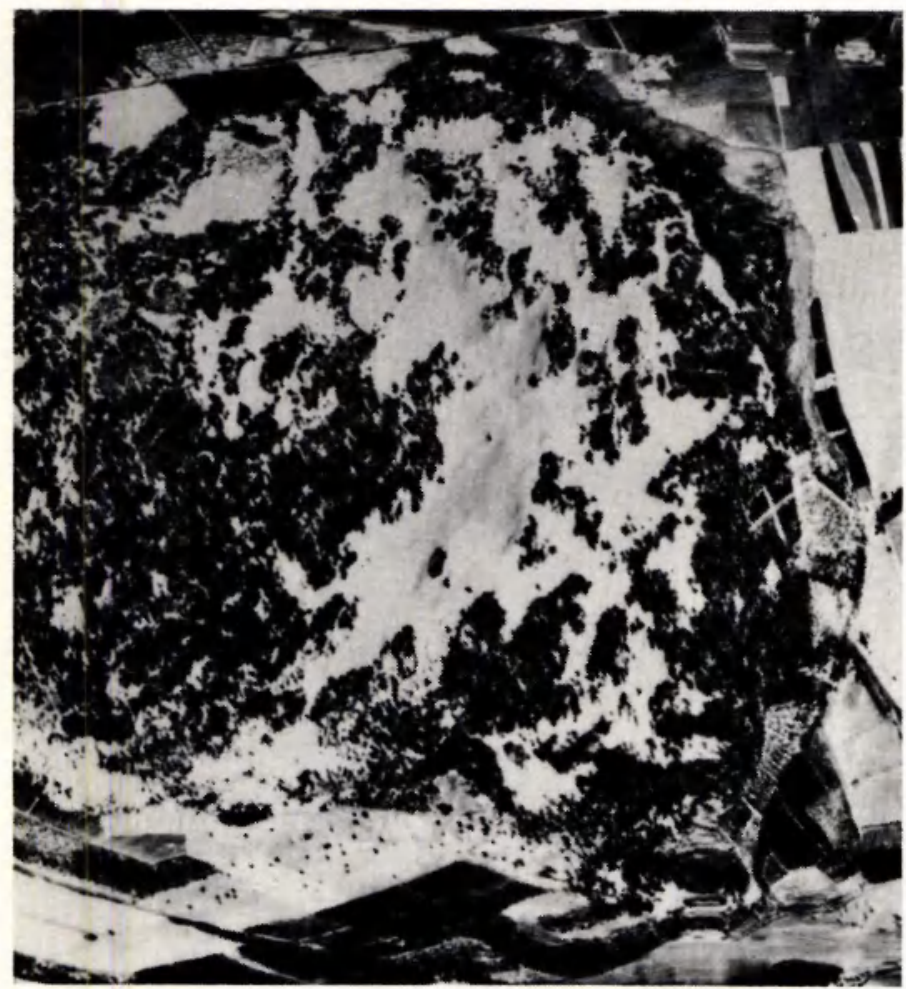

Fig. 5. Same area as Fig. 4 on a day-time IRLS picture ( $10 \mathrm{~m} 00)$. Contrasts in the sand hills reflect differential heating due to different slopes and aspects of the hill sides.

Heather, for example, comes out much colder for other reasons. The pine vegetation on the slope shows much warmer than in the frost hole.

Fig. 4 shows a night picture of a bare sand dune area. Dark regions in the sand correspond to gullies and blown out areas between sand hills. In this case the emissivity of the sand is low (about $90 \%$ ), making sand look several degrees cooler than it actually is because it reflects radiation from a sky of low effective temperature. Temperatures of the sand are therefore not to be compared directly with those of vegetation covers that have much higher emissivities (about $96 \%$ ). Within the bare sand area however the differences in tone may be interpreted as differences in temperature and clearly show cold streams and basins in the lower areas.

Fig. 5 is a day-time picture of the same area. In this case differences of temperature in the sand are due to slope and exposition of these slopes relative to the sun. In this case too differences due to topographic effects are comparable in magnitude to those caused by a cover of low vegetation. The range between extremes of surface temperatures measured in the field was $7{ }^{\circ} \mathrm{C}$. 


\section{Acknowledgments}

Thanks are due to NIWARS (Netherlands Interdepartmental Working Community for the Application of Remote Sensing techniques) for its cooperation in producing IRLS pictures of the area and allowing their publication, to Professor Dr Ir J. Schenk for reading the manuscript and to $\mathrm{Mr} \mathrm{M}$. Scharringa and $\mathrm{Dr} \mathrm{Ph}$. Stoutjesdijk for stimulating discussions.

\section{References}

Buetner, K. J. K. \& C. D. Kern, 1965. The determination of infrared emissivities of terrestrial surfaces. J. geophys. Res. 70: 1329-1337.

Businger, J. A., M. Miyake, A. J. Dyer \& E. F. Bradley, 1967. On the direct determination of the turbulent heat flux near the ground. J. appl. Meteor. 6: 1025-1029.

Cars'aw, H. S. \& J. C. Jaeger, 1950. Conduction of heat in solids. Oxford University Press, Oxford.

Lorenz, D., 1968. Temperature measurements of natural surfaces using infrared radiometers. Appl. Optics $7(9): 1705-1710$.

Priestly, C.H.B., 1959. Turbulent transfer in the lower atmosphere. University of Chicago Press, Chicago. Wijk, W. R. van (Ed.), Physics of plant environment. North Holland Publishing Company, Amsterdam 